\title{
MS18-01 | Electrochemical Energy Storage beyond Lithium
}

Ehrenberg, Helmut (Karlsruher Institut für Technologie, Eggenstein-Leopoldshafen, GER)

Electrochemical energy storage beyond lithium is highly relevant for sustainable energy technology. New electrode concepts are needed for the intercalation of larger monovalent $\left(\mathrm{Na}^{+}, \mathrm{K}^{+}\right)$or multivalent ions $\left(\mathrm{Mg}^{2+}\right)$. One example for a promising Na-ion battery is presented based on symmetrical NASICON-structured $\mathrm{Na}_{2} \mathrm{VTi}\left(\mathrm{PO}_{4}\right)_{3}$ electrodes [1]. Operando synchrotron diffraction and absorption spectroscopy unravel the underlying sodium storage and charge compensation mechanisms. Model systems for multivalent-ion insertion are also hybrid batteries with two mobile metal ions in the electrolyte, where $\mathrm{Mg}$ is plated at the negative electrode, while Li- or Na-ions are inserted at the positive electrode [2,3]. Recent results on the working mechanisms in such hybrid batteries are revealed by operando synchrotron diffraction and ex situ XPS. Appropriate material combinations for Mg-batteries with insertion-type positive electrodes and sufficiently high cell voltages are still lacking. For example, $\mathrm{V}_{2} \mathrm{O}_{5}$ works only with unstable electrolytes in contact with $\mathrm{Mg}$-metal and steel housing. The Mg-insertion mechanism was therefore investigated for a full cell with $\mathrm{Mg}_{x} \mathrm{Mo}_{6} \mathrm{~S}_{8}$ as a suitable negative electrode [4].

This work contributes to research performed at CELEST (Center for Electrochemical Energy Storage Ulm-Karlsruhe) and was funded by the German Research Foundation (DFG) under Project ID 390874152 (POLiS Cluster of Excellence).

[1] Wang, D. et al., Nature Communications 2017, 8, 15888.

[2] Bian, X. et al., Mater. Chem. A 2017, 5, 600.

[3] Fu, Q. et al., Electrochim. Acta 2018, 277, 20.

[4] Fu, Q. et al., J. Am. Chem. Soc. 2019, 141, 2305. 